\title{
PDUFA: The US Senate should clean up its act
}

The Prescription Drug User Fee Act (PDUFA)-which requires companies to pay fees to the US Food and Drug Administration (FDA) for the review of drugs and biologics-was enacted by Congress in 1992 and expires at the end of this month, when it is up for renewal. It was intended to significantly shorten the amount of time it takes to get a drug through the regulatory approval process both by allowing FDA, through the fees collected, to hire some 600 additional qualified reviewers and by streamlining the Byzantine steps of the review process.

It worked. Drug approval times have dropped significantly-in 1996 , down from 25 months in the early 1990 s to approximately 16 months, and in some expedited cases, 3 or 4 months. Concerns remain about the amount of time required to get a drug through clinical trials, but PDUFA has certainly steered the agency in the right direction.

Prospects looked bright when draft legislation-S. 830, the "Food and Drug Administration Modernization and Accountability Act of 1997," introduced by Senator Jim Jeffords (R. Vt.) - began to make its way through the bill approval process earlier this year. Its drug and biologics provisions include reauthorization of PDUFA for five years and new FDA drug approval performance objectives to further expedite the drug approval process. Over the past months, however, the bill has been derailed by various political schemes to attach to it more extensive and controversial FDA reform amendments.

This political endgame has created a good deal of uncertainty about new drug application submissions-get them in before September 30 , or wait until the program is renewed?-not to mention the question of how various procedural deadlines for drugs already in process will be met in the face of continued delay.

The Senate should separate the wheat from the chaff on S.830. It should gather up the items-including PDUFA renewal and enhancement-on which it has gained consensus and table the rest.

It's time to get the ball rolling again. With a wave of biotechnology products coming to market and more than $\$ 40$ billion worth of the pharmaceutical industry's biggest products about to go off-patent in less than five years, approval of this legislation is crucial so as not to jeopardize the considerable progress that has resulted from the user fee program to date.

FDA reform measures beyond those on which agreement has already been reached should also be taken forward-and the political and philosophical debate about the overall extent and kind of food and drug regulation continued-but not at the expense of this measurably successful first effort.

\section{Gene therapy: Better vectors, less hype}

In December 1995, an ad hoc committee to review gene therapy protocols-appointed by Harold Varmus, the director of the US National Institutes of Health, and cochaired by Stuart Orkin (Harvard Medical School) and Arno Motulsky (University of Washington, Seattle)-sent the gene therapy community scrambling. Although the panel stated that gene therapy is a natural extension of the basic sciences into therapeutic applications, it also concluded that clinical trial results had been hyped and that the enormous potential of the field had not been realized, calling for a return to first principles. No one on the panel advocated a halt to human trials, and in fact the report explicitly cited their necessity. The committee did, however, make clear that two critical steps of somatic gene therapy--delivery of a gene to the right cell and the subsequent maintenance of gene expression-needed a lot more work, particularly in the area of vector design.

What has happened since then? Research has taken a metaphoric step backward with an eye on the prospect of two steps forward. At the time of the 1995 "Orkin" report, oncoretroviral and adenoviral vector based delivery systems dominated the field. These two vector types are still at the forefront of gene therapy research. What has changed, however, is that the limitations of these systems are no longer obscured beneath the advantages that each has to offer.

Now, alternative viral vectors that probably would not have been considered for their potential in gene therapy are also making headlines. HIV, for example. While it has the reported ability to infect nondividing cells, other attributes clearly mitigate against this use. But in this issue, Didier Trono and colleagues (p. 871) demonstrate that removal of the putative virulence genes does not inhibit HIV's transducing potential, thus making what would earlier have seemed to be a science fiction fantasy into a tenable approach. Whereas advocates of either adenoviral or oncoretroviral vectors have previously seemed to ignore the inherent potential of the "competing" system, the individual merits of adenoviruses and retroviruses have also been combined in a novel chimeric viral delivery system (p. 866).

Since the Orkin report, it has been more widely appreciated that the natural tropism of a virus, while advantageous to its own replication cycle, is not always optimal for a gene delivery protocol. A number of published reports, including those from the laboratories of Thomas Wickham (Nature Biotechnology 14:1570, 1996), David Curiel (Nature Biotechnology 14:1574, 1996), and Daniel Meruelo (Nature Biotechnology 15:763, 1997), have explored methods to redirect the targeting that has evolved to ensure viral infectivity in ways that may be more suitable to the aims of gene therapy.

Are these research efforts reflective of a new sober attitude toward gene therapy's accomplishments? They seem to be. Researchers have continued to focus on the seemingly modest goals laid out in the 1995 report-refining vector design for directed gene delivery and stable expression.

This return to first principles, combined with a frank appreciation of what happens when an entire field begins to believe its own press, should help to continue to move gene therapy in the direction of its largest and most important ambitions. 